\title{
An Investigation on the Micro Structural and Elemental Composition of Sugarcane Bagasse Ash Blended Concrete using SEM and EDS Technique
}

\author{
Chidanand Patil $^{\mathrm{a}^{*}}$, P.B.Kalburgi ${ }^{\mathrm{b}}$, M.B.Patil ${ }^{\mathrm{c}}$, K.B.Prakash ${ }^{\mathrm{d}}$ \\ ${ }^{a}$ Civil Engineering Department, KLEDRMSSCET, Belagavi-590008, India \\ ${ }^{b}$ Civil Engineering Department, BEC, Bagalkot-India \\ ${ }^{c}$ Civil Engineering Department, GSKSJTI, Bengaluru-560001, India \\ ${ }^{d}$ Civil Engineering Department, GEC, Haveri-581110, India
}

Received: 09 January 2018; Accepted: 15 March 2018; Published: 08 May 2018

\begin{abstract}
Sugarcane bagasse ash (SBA) is a solid waste obtained from the boilers of sugar factories after the combustion of sugarcane bagasse. Sugarcane bagasse ash mainly consists of amorphous silica and can be used as a supplementary cementitious material in the production of concrete. In the present study, the physical properties of sugarcane bagasse ash, namely, particle size distribution, surface area, specific gravity, morphology and chemical properties like elemental composition of SBA and ordinary Portland cement (OPC) have been investigated. The microstructural observations were made using Scanning Electron Microscope (SEM). Elemental compositions were analyzed and images coupled to microanalysis by Energy dispersive spectroscopy (EDS). The microstructure observations and elemental characterization of cement concrete matrix was also carried out after 28 days of curing. Blended cement concrete specimens were prepared using SBA up to $30 \%$ in regular intervals of $10 \%$ by weight of pure Portland cement, coarse and fine aggregate, tap water and superplastisizer. SEM results indicates that substitution of SBA particles by Portland cement produces dense matrix as compared to control mix and EDS analysis shows fluctuations in calcium and silica concentrations as the cement replacement level increases in the blended cement concrete.
\end{abstract}

Index Terms: Sugarcane bagasse ash, SEM, EDS, particle size, surface area.

(C) 2018 Published by MECS Publisher. Selection and/or peer review under responsibility of the Research Association of Modern Education and Computer Science.

* Corresponding author. Tel.: +919986269940

E-mail address: chidu.patil@gmail.com 


\section{Introduction}

Sugar cane is a type of giant grass belonging to the family, botanically known as 'sachrum'. Sugarcane, with its high fibre and carbohydrate content, constitutes an important renewable source of energy. During its long growth period of 10 to 16 months, this plant converts good amount of solar energy into sugar and cellulose. So far as sugar cane production is concerned, Brazil is the world's largest producer of sugarcane followed by India. The production in Brazil is of the order of 260 million tons per annum followed by India with 254 million tons [1].

Out of 110 million tons of crystal sugar produced annually, $60 \%$ is being produced from sugarcane and the remaining $40 \%$ from the beet sugar industry. Many byproducts such as bagasse, bagasse ash, molasses etc., are generated during the production of sugar from sugarcane. When sugar cane is crushed in the milling plant of sugar factories for extracting juice, the fibrous residue left-over after the extraction of juice is known as bagasse and in some countries is known as migasse. The term bagasse is derived from the French and Spanish word "bagazo" given to the husks of grapes or olives (waste materials) left over after extracting their contents by pressing. Bagasse contains about 47-50\% moisture, $48-50 \%$ fibre and about 1-3\% dissolved solids including sugar [1].

Initially, bagasse was mainly used for paper production. Due to its relatively high calorific value, nowadays it is also used as a fuel feedstock in the cogeneration boiler of the sugar industry to produce electricity [2]. Because of considerable income generation associated with this process, almost all the sugar plants in India and other sugar-producing countries have implemented a cogeneration system.

The ash produced by the controlled burning of bagasse at a temperature of $600-800^{\circ} \mathrm{C}$ is called Sugarcane Bagasse Ash (SBA). Enormous quantity of SBA (67,000 tons/day) is generated in India as a waste material from cogeneration boilers in sugar factories. This waste material is directly disposed to nearest land which causes severe environmental problems [3]. Due to the presence of lightweight fibrous unburnt matter and extreme black color, disposal of bagasse ash leads to severe pollution to the water bodies and land adjacent to the disposal area. Moreover, the presence of fine fraction can lead to severe air pollution. Most sugar industries are located in the villages and residual sugarcane bagasse ash from the plants is directly dumped to the agricultural land in these villages [4]. Hence, it becomes imperative to find reuse of bagasse ash instead of disposal.

Sugarcane bagasse ash mainly consists of amorphous silica and hence this byproduct can be used as a supplementary cementitious material in cement based paste and concrete. This further minimizes environmental problems associated with the disposal of bagasse ash [4]. Several researchers have suggested that the utilization of SBA as a mineral admixture in blended cement concrete can improve both mechanical and durability properties of concrete [5-8].

G.C. Cordeiro et.al. [4] Studied the processing and characterization of highly reactive SBA. Initially, different calcination temperatures were allowed to obtain SBA with amorphous silica and low carbon content. Detailed measurements of structural state, pozzolanic activity and loss on ignition were carried out in order to compare the performance of the different SBAs. Subsequently, one optimal SBA was characterized according to pozzolan specifications. N.B. Singh et.al [7] reported that sugarcane bagasse ash acts as a binding material and the compressive strength of SBA concrete increases with hydration time. Guilherme Chagas Cordeiro et.al. [10] Studied the influence of different mechanical grinding configurations, on the physical characteristics such as particle size distribution, specific surface area and pozzolanic activity of SBA. The specific grinding energy required to obtain the different combination products has also been estimated. Nuntachai Chusilp et.al., [11] reported that the development of compressive strengths of mortars containing ground bagasse ash with high loss on ignition (LOI) was slower than that of mortar containing ground bagasse ash with low LOI.

The current paper describes physico-chemical properties of SBA and OPC namely, particle size distribution, surface area, specific gravity, morphology and elemental analysis. The cement concrete specimens blended with different percentages of SBA namely, 0\% (SBA0), 10\% (SBA10), 20\% (SBA20) and 30\% (SBA30) 
replaced with OPC by weight were cured under tap water for a period of 28 days. After 28 days of age, specimens were crushed under compression testing machine (CTM). Then the samples of this crushed material were taken for the analysis of microstructure and elemental composition using SEM images coupled with EDS analysis.

\section{Experimental Investigation}

\subsection{Materials}

\subsubsection{Ordinary Portland Cement (OPC)}

Ordinary Portland cement of 43 grade (OPC 43) was used for all concrete mixes. The cement used was fresh and without any lumps. The testing of cement was carried out as per Indian Standard Specifications IS: 81121989 [12]. The basic properties of cement are shown in Table 1.

Table 1. Properties of Cement

\begin{tabular}{|c|c|c|c|}
\hline \multicolumn{2}{|l|}{ Properties } & Test results & Norms as per I.S. 8112-1989 \\
\hline \multicolumn{2}{|c|}{ Initial setting time } & $64 \mathrm{~min}$ & Not less than $30 \mathrm{~min}$ \\
\hline \multicolumn{2}{|c|}{ Final setting time } & $189 \mathrm{~min}$ & Not more than $600 \mathrm{~min}$ \\
\hline \multicolumn{2}{|c|}{ Standard consistency } & $28 \%$ & In between $26 \%$ to $32 \%$ \\
\hline \multicolumn{2}{|c|}{ Specific gravity } & 3.15 & In between 2.5 to 3.5 \\
\hline \multirow{3}{*}{$\begin{array}{l}\text { Compressive } \\
\text { strength }\end{array}$} & 3 days & $24.88 \mathrm{~N} / \mathrm{mm}^{2}$ & Not less than $23 \mathrm{MPa}$ \\
\hline & 7 days & $34.33 \mathrm{~N} / \mathrm{mm}^{2}$ & Not less than $33 \mathrm{MPa}$ \\
\hline & 28 days & $50 \mathrm{~N} / \mathrm{mm}^{2}$ & Not less than $43 \mathrm{MPa}$ \\
\hline
\end{tabular}

\subsubsection{Aggregates}

Natural river sand of size below $4.75 \mathrm{~mm}$ conforming to zone II was used as fine aggregate. Natural crushed stone with $20 \mathrm{~mm}$ down size was used as coarse aggregate. Table 2 shows the test results of basic properties of fine aggregate and coarse aggregate. Both fine and coarse aggregate are in compliance to the Indian Standard Specifications IS 383-1970 [13].

Table 2. Properties of Fine and Coarse Aggregate

\begin{tabular}{|l|l|l|}
\hline Properties & Fine Aggregate & Coarse Aggregate \\
\hline Specific gravity & 2.65 & 2.80 \\
\hline Water absorption & $1.23 \%$ & $0.98 \%$ \\
\hline Surface moisture content & Nil & Nil \\
\hline Crushing strength & --- & $18.68 \%$ \\
\hline Impact value & --- & $11.64 \%$ \\
\hline
\end{tabular}

\subsubsection{Water}

Tap water conforming to the Indian Standard Specifications IS: 456-2009 [14] for concreting and curing was used during the experimental work. 


\subsubsection{Sugarcane Bagasse Ash (SBA)}

The sugarcane bagasse ash was obtained from Panchaganga sugar industry, Ichalakaranji, Maharashtra state, India. Each ton of sugarcane generates approximately $26 \%$ of bagasse [15]. The bagasse ash obtained after the combustion of bagasse at a temperature of $600-800^{\circ} \mathrm{C}$ presents a chemical composition dominated by silicon dioxide $\left(\mathrm{SiO}_{2}\right)$. The composition of sugarcane bagasse and sugarcane bagasse ash depends on the variety of cane crushed, quality of water used during irrigation, type of soil, temperature at which bagasse is burnt.

\subsubsection{Super Plasticizer}

The super plasticizer Conplast SP430 was used. Super plasticizer permits reduction in water usage up to $25 \%$. It also helps in providing better compaction and enhances the workability of the mix.

\section{Methods}

\subsection{Processing/Sieving of SBA(Sugarcane bagasse ash)}

The raw SBA collected from the sugar industry was ground and sieved through $90 \mu \mathrm{m}$. Sieving was carried out to remove the unburnt carbon particles and to increase the surface area of SBA particles.

\subsection{Physical and Chemical Characterization of SBA (Sugarcane bagasse ash) and OPC(Ordinary Portland cement)}

The use of SBA as a partial replacement for Portland cement can improve both mechanical and durability properties of concrete due to the physical and chemical effects provided by SBA. The physical effects are mainly associated with their influence on the packing characteristics of the solid mixture. On the other hand chemical effects are linked to their capability of providing amorphous silica that will react with $\mathrm{Ca}(\mathrm{OH})_{2}$ (calcium hydroxide) in the presence of water during cement hydration.

Physical characteristics namely, particle size distribution, surface area, morphology and specific gravity were determined. Zeta size of SBA and OPC particles were investigated using HORIBA zeta analyzer. The samples were dispersed in water by sonicating for 5 minutes and then transferred to cuvette and measured by laser particle size analyzer. The surface area of SBA and OPC were measured according to the Nitrogen (BET apparatus) using Smart sorb-93 surface area analyzer. The specific gravity of processed SBA and OPC were determined by using standard Lechatelier flask and kerosene (density $0.73 \mathrm{~g} / \mathrm{cc}$ ) as per Indian Standards IS: 1727-2004. Processed SBA has lower specific gravity (2.1) compared to OPC (3.15). Specific gravities of coarse and fine aggregates were determined as per Indian Standards IS: 1727-2004. Morphology of SBA and OPC were examined by Scanning Electron Microscope. The elemental composition of SBA and OPC were further investigated using Scanning Electron Microscope (SEM) images coupled to microanalysis by Energy dispersive spectroscopy (EDS).

Chemical composition in terms of oxides was carried out by X-ray fluorescence (XRF), using a Bruker model S4, equipped with goniometer of $4 \mathrm{~kW}$ rhodium X-ray tube.

\subsection{Mix Proportions and Casting Of Concrete Specimens}

In this experimental work, four different proportions of concrete mixes (SBA ranging from 0-30\% by weight of cement) including the control units were prepared with a water binder $(\mathrm{W} /(\mathrm{C}+\mathrm{SBA}))$ ratio of 0.44 . These mixes were designated as SBA0 for control; and SBA10, SBA20, and SBA30 for blended cement concretes 
containing 10, 20 and 30\% of sugarcane bagasse ash respectively. Mix design was carried out as per IS: 102622009. The mix proportions are presented in Table 3. First the Portland cement and SBA were thoroughly mixed in a 0.04 Cubic meter capacity pan type concrete mixer in the laboratory. Before starting the mixer machine, the mixer drum was fully washed using portable water and allowed to dry. Coarse and fine aggregates and $70 \%$ of total calculated water was added first in the mixer machine and allowed to mix for 3-4 minutes. Then cement, SBA and remaining water was added and the mixing continued until the concrete gets homogeneous. Before casting the specimens, machine oil was smeared on the inner surface of the cast iron mould. For mixes SBA0 to SBA30, concrete was poured into the moulds of size $150 \mathrm{~mm} \times 150 \mathrm{~mm} \times 150 \mathrm{~mm}$ and compacted thoroughly using table vibrator. After casting, all specimens were left covered in the laboratory for 24 hours. The specimens were then demoulded and cured under water for a period of 28 days.

Table 3. Mix Proportions of SBA Blended Cement Concrete

\begin{tabular}{|l|l|l|l|l|l|l|l|}
\hline \multirow{2}{*}{$\begin{array}{l}\text { Mix } \\
\text { Designation }\end{array}$} & \multirow{2}{*}{$\begin{array}{l}\text { SBA } \\
(\%)\end{array}$} & \multirow{2}{*}{$\begin{array}{l}\mathrm{W} /(\mathrm{C}) \text { or } \\
\text { W/(C+SBA })\end{array}$} & $\begin{array}{l}\text { Quantities } \\
\left(\mathrm{Kg} / \mathrm{m}^{3}\right)\end{array}$ & $\begin{array}{l}\text { SBA } \\
\left(\mathrm{Kg} / \mathrm{m}^{3}\right)\end{array}$ & $\begin{array}{l}\text { Cement } \\
\left(\mathrm{Kg} / \mathrm{m}^{3}\right)\end{array}$ & $\begin{array}{l}\text { Sand } \\
\left(\mathrm{Kg} / \mathrm{m}^{3}\right)\end{array}$ & $\begin{array}{l}\text { Aggregate } \\
\left(\mathrm{Kg} / \mathrm{m}^{3}\right)\end{array}$ \\
\hline SBA0 (Control) & 0 & 0.44 & 170 & 0 & 386.36 & 686 & 1245 \\
\hline SBA10 & 10 & 0.44 & 170 & 38.63 & 347.73 & 686 & 1245 \\
\hline SBA20 & 20 & 0.44 & 170 & 77.27 & 309.09 & 686 & 1245 \\
\hline SBA30 & 30 & 0.44 & 170 & 115.90 & 270.46 & 686 & 1245 \\
\hline
\end{tabular}

\subsection{SEM and EDS Analysis}

Scanning electron microscopy (SEM) and Energy dispersive spectroscopy (EDS) was used in the analysis of microstructure and chemical composition of blended cement concrete in the hardened state. After 28 days of curing, the specimens (from SBA0 to SBA30) were dried and then crushed under compressive testing machine (CTM). A small portion of mortar part were removed from each mix around the coarse aggregates, then the mortar was ground and only the cementitious matrix was used for SEM-EDS analysis. SEM images were taken on the blended cement matrix to examine the microstructure properties. Before SEM and microanalysis, the samples were coated with a layer of carbon in argon gas atmosphere at a high vaccum of $5.0 \times 10^{-6}$ Torrs, in order to make them electrically conductive in nature. SEM (JSM-IT300) accompanied by an EDS analyzer, supplied by JEOL Limited, was used for the image processing. The JSM-IT300 provides a large specimen chamber which can accommodate specimens containing multiple samples at a time.

EDS analysis was also carried out to determine the elemental composition of cementitious matrix in the transition zone. EDS spectra were acquired with the help of INCA system software which is used by the Oxford spectrometer. The working distance was maintained at $13 \mathrm{~mm}$ and the probe currents $(64.8 \mu \mathrm{A}-67 \mu \mathrm{A})$ in order for the EDS analyzer to work properly.

\section{Results and Discussion}

\subsection{Physical Properties of SBA and OPC}

Table 4 presents physical properties of SBA and OPC. The particle size distributions of SBA and OPC are as shown in Fig. 1(a) and Fig. 1(b). The ashes exhibits similar particle size distributions with mean grain size as $1.3 \mathrm{~nm}$. The mean particle size of OPC was found to be $1191.4 \mathrm{~nm}$. This was further confirmed by specific surface area of SBA and OPC. The surface area of SBA and OPC are found to be $7.832 \mathrm{~m}^{2} / \mathrm{gm}$ and $0.752 \mathrm{~m}^{2} / \mathrm{gm}$ respectively. The surface area of SBA is nearly about ten times that of OPC due to the presence of light weight 
fine particles. As a matter of fact, each particle will participate in hydration reactions based on the particle size and surface area.

Table 4. Physical Properties of SBA and OPC

\begin{tabular}{|c|c|c|}
\hline \multirow{2}{*}{ Physical property } & \multicolumn{2}{|c|}{ Material } \\
\cline { 2 - 3 } & SBA & OPC \\
\hline Mean grain size $(\mathrm{nm})$ & 1.3 & 1191.4 \\
\hline Surface area $\left(\mathrm{m}^{2} / \mathrm{gm}\right)$ & 7.832 & 0.752 \\
\hline Specific gravity & 2.1 & 3.15 \\
\hline Density $\left(\mathrm{kg} / \mathrm{m}^{3}\right)$ & 1025 & 410 \\
\hline
\end{tabular}

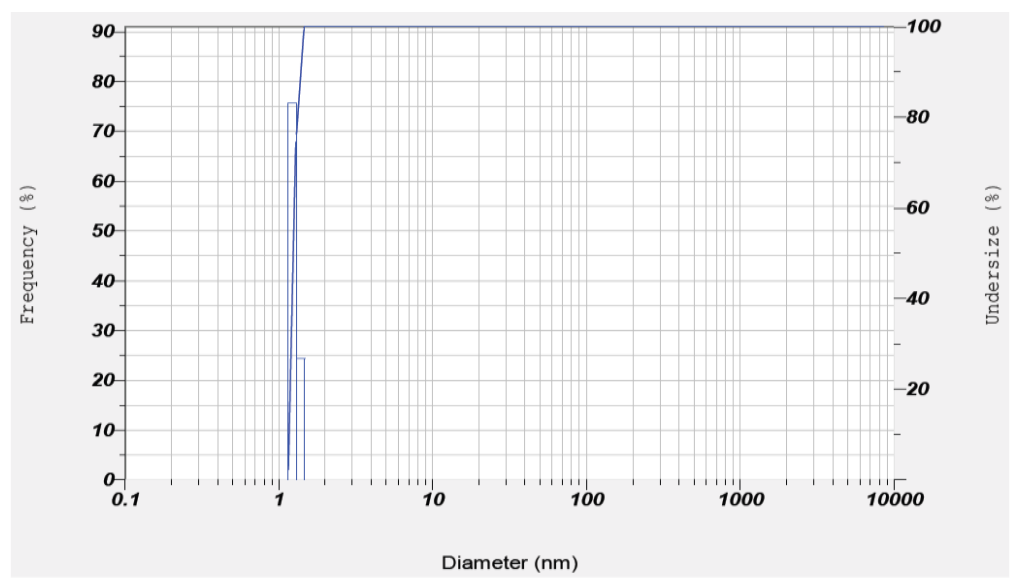

Fig.1(a). Particle size distribution of SBA

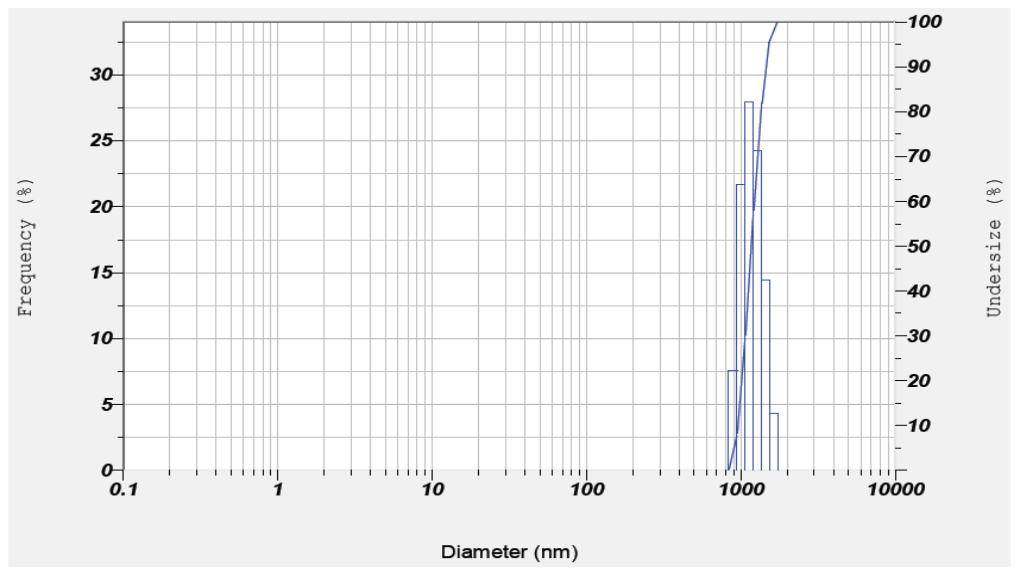

Fig.1(b). Particle size distribution of OPC

4.2. Morphology and Elemental Composition of OPC (Ordinary Portland Cement) and SBA (Sugarcane Bagasse Ash) 
For identification and characterization of mineral phases and morphology of OPC and SBA particles, SEMEDS analysis is the best and most widely used method. Morphology of OPC and fine fibrous particles of SBA are presented in Fig. 2(a) and Fig. 3(a). The cement particles were angular and irregular while SBA particles had smooth surface with high porosity that is spongy in nature and large surface area. EDS analyses were also used in conjunction with SEM to obtain the elemental composition of SBA and OPC. The EDS analysis of selected area (see rectangle in Fig. 2(a)) shows that the OPC particles contains predominately calcium $(\mathrm{Ca})$, oxygen $(\mathrm{O})$ and silica $(\mathrm{Si})$ with trace amounts of aluminium $(\mathrm{Al})$, iron $(\mathrm{Fe})$, potassium $(\mathrm{K})$, sodium $(\mathrm{Na})$ as shown in Fig. 2(b). Similarly EDS analysis of SBA (see rectangle in Fig. 3(a)) shows that the selected particles contains predominately silica and oxygen with lesser amount of potassium, calcium, iron, chloride $(\mathrm{Cl})$, phosphorus $(\mathrm{P})$ and magnesium $(\mathrm{Mg})$ as shown in Fig. 3(b).

Chemical properties of OPC and SBA are represented in Table 5. SEM-EDS analysis of OPC and SBA shows similar chemical composition but variation in proportion is observed.

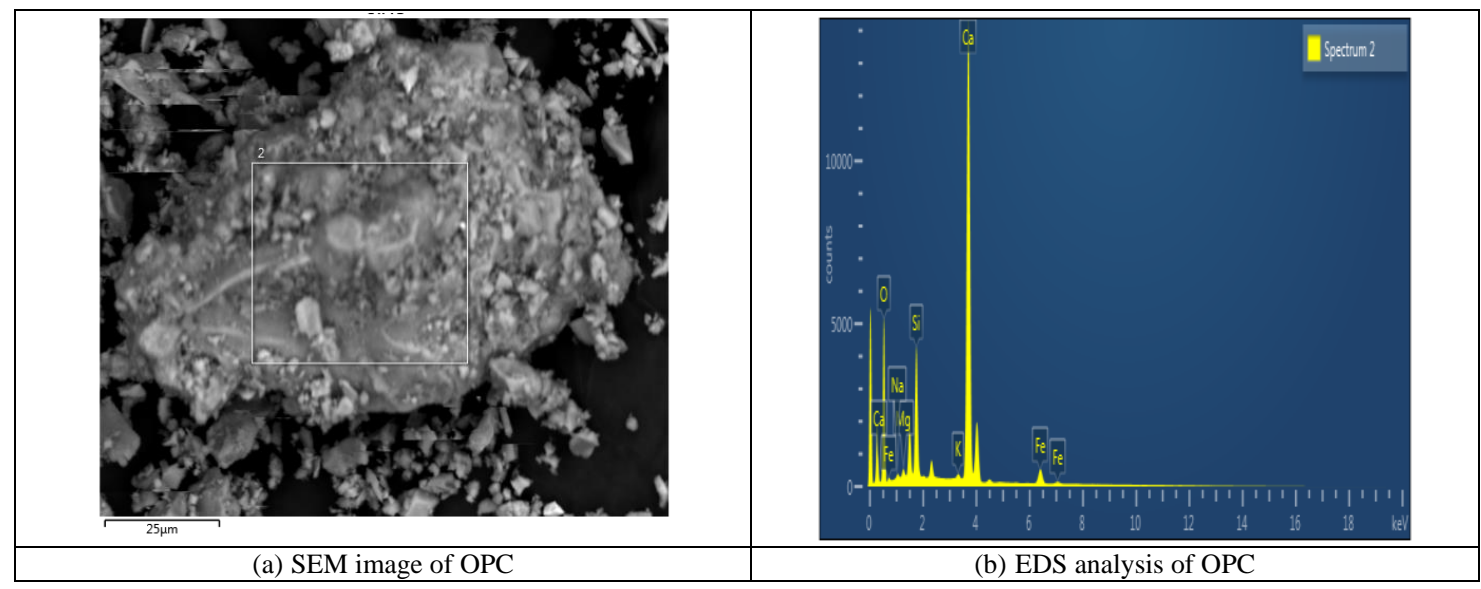

Fig.2. SEM Micrographs and EDS Analysis of OPC Particles

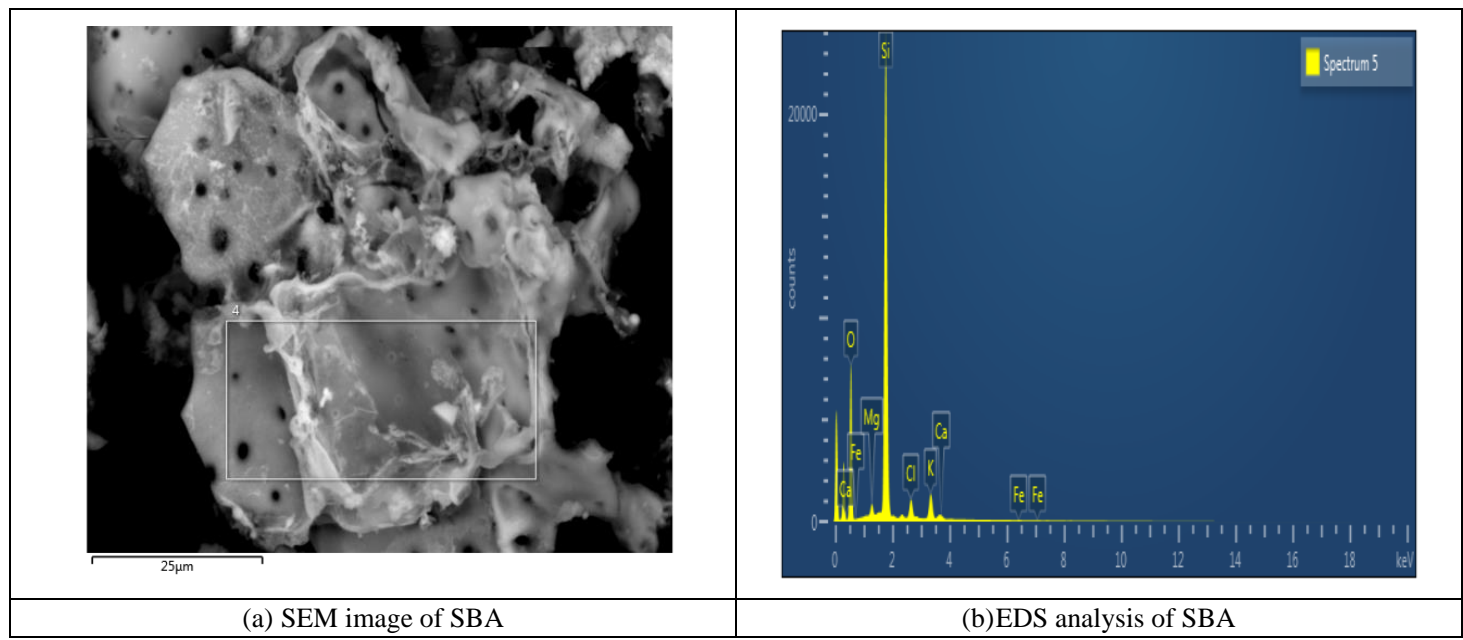

Fig.3. SEM Micrographs and EDS Analysis of SBA Particles 
Table 5. Elemental Composition of SBA and OPC

\begin{tabular}{|l|l|l|}
\hline Element & OPC $($ wt $\%)$ & SBA $(w t \%)$ \\
\hline $\mathrm{O}$ & 34.65 & 49.5 \\
\hline $\mathrm{Si}$ & 7.92 & 41.16 \\
\hline $\mathrm{S}$ & 1.25 & 0.45 \\
\hline $\mathrm{Ca}$ & 46.70 & 0.53 \\
\hline $\mathrm{Fe}$ & 4.32 & 0.19 \\
\hline $\mathrm{Al}$ & 3.61 & -- \\
\hline $\mathrm{K}$ & 0.41 & 4.20 \\
\hline $\mathrm{Mg}$ & 0.62 & 1.22 \\
\hline $\mathrm{Na}$ & 0.51 & -- \\
\hline $\mathrm{Cl}$ & -- & 2.75 \\
\hline
\end{tabular}

\subsection{XRF analysis of $O P C$ and $S B A$}

The oxide composition of OPC and SBA was determined using X-ray fluorescence spectrometer (XRF) and the results are tabulated in Table 6.

Table 6. Chemical Characterization of SBA and OPC

\begin{tabular}{|c|c|c|c|}
\hline Chemical composition (\%) & OPC & SBA & Requirement of ASTM C 618 \\
\hline $\mathrm{SiO}_{2}$ & 23.22 & 79.82 & -- \\
\hline $\mathrm{TiO}_{2}$ & 0.30 & 0.25 & -- \\
\hline $\mathrm{Al}_{2} \mathrm{O}_{3}$ & 5.89 & 1.88 & -- \\
\hline $\mathrm{MnO}$ & 0.00 & 0.04 & -- \\
\hline $\mathrm{Fe}_{2} \mathrm{O}_{3}$ & 2.06 & 1.09 & -- \\
\hline $\mathrm{CaO}$ & 62.34 & 2.04 & -- \\
\hline $\mathrm{MgO}$ & 0.95 & 1.98 & -- \\
\hline $\mathrm{Na}_{2} \mathrm{O}$ & 0.19 & 0.19 & -- \\
\hline $\mathrm{K}_{2} \mathrm{O}$ & 0.34 & 3.82 & -- \\
\hline $\mathrm{P}_{2} \mathrm{O}_{5}$ & 0.41 & 1.36 & $<4$ \\
\hline $\mathrm{SO}$ & 0 & 0 & $<10$ \\
\hline $\mathrm{LOI}$ & 3.41 & 7.09 & $>70$ \\
\hline $\mathrm{SiO}_{2} \mathrm{O}_{3}+\mathrm{Fe}_{2} \mathrm{O}_{3}$ & & 82.79 & \\
\hline & & & - \\
\hline
\end{tabular}

The XRF chemical analysis of OPC shows high calcium oxide $(\mathrm{CaO})$ and silicon dioxide $\left(\mathrm{SiO}_{2}\right)$ contents of $62.34 \%$ and $23.32 \%$ respectively. The oxide composition of SBA (Table 6) show that SBA is mainly composed of silicon dioxide $\left(\mathrm{SiO}_{2}\right)$, alumina $\left(\mathrm{Al}_{2} \mathrm{O}_{3}\right)$ and iron oxide $\left(\mathrm{Fe}_{2} \mathrm{O}_{3}\right)$ and it is found that the sum of $\mathrm{SiO}_{2}, \mathrm{Al}_{2} \mathrm{O}_{3}$ and $\mathrm{Fe}_{2} \mathrm{O}_{3}$ for SBA is higher than the minimum requirement stated for Class $\mathrm{N}$ pozzolan $(>70 \%)$ according to ASTM C618 (2003). Moreover, the percentage of sulphur trioxide $\left(\mathrm{SO}_{3}\right)$ and the loss on ignition (LOI) for SBA is well below the maximum requirement of $4 \%$ and $10 \%$ respectively as specified by the ASTM C618 standard. The rest of the oxides such as titanium dioxide $\left(\mathrm{TiO}_{2}\right)$, magnesium oxide $(\mathrm{MgO})$, potassium oxide $\left(\mathrm{K}_{2} \mathrm{O}\right)$ and diphosphorus pentoxide $\left(\mathrm{P}_{2} \mathrm{O}_{5}\right)$ are present in trace concentrations below $1.5 \%$. It is important to note that the content of sodium oxide $\left(\mathrm{Na}_{2} \mathrm{O}\right)$ in the ash is below $0.2 \%$. The SBA shows a different composition to those published previously, mainly in concentration of $\mathrm{SiO}_{2}$ (79.82\%), $\mathrm{Al}_{2} \mathrm{O}_{3}(5.89 \%)$ and $\mathrm{Fe}_{2} \mathrm{O}_{3}(2.06 \%)$ [11]. 


\subsection{SEM and EDS Observation of SBA Blended Concrete}

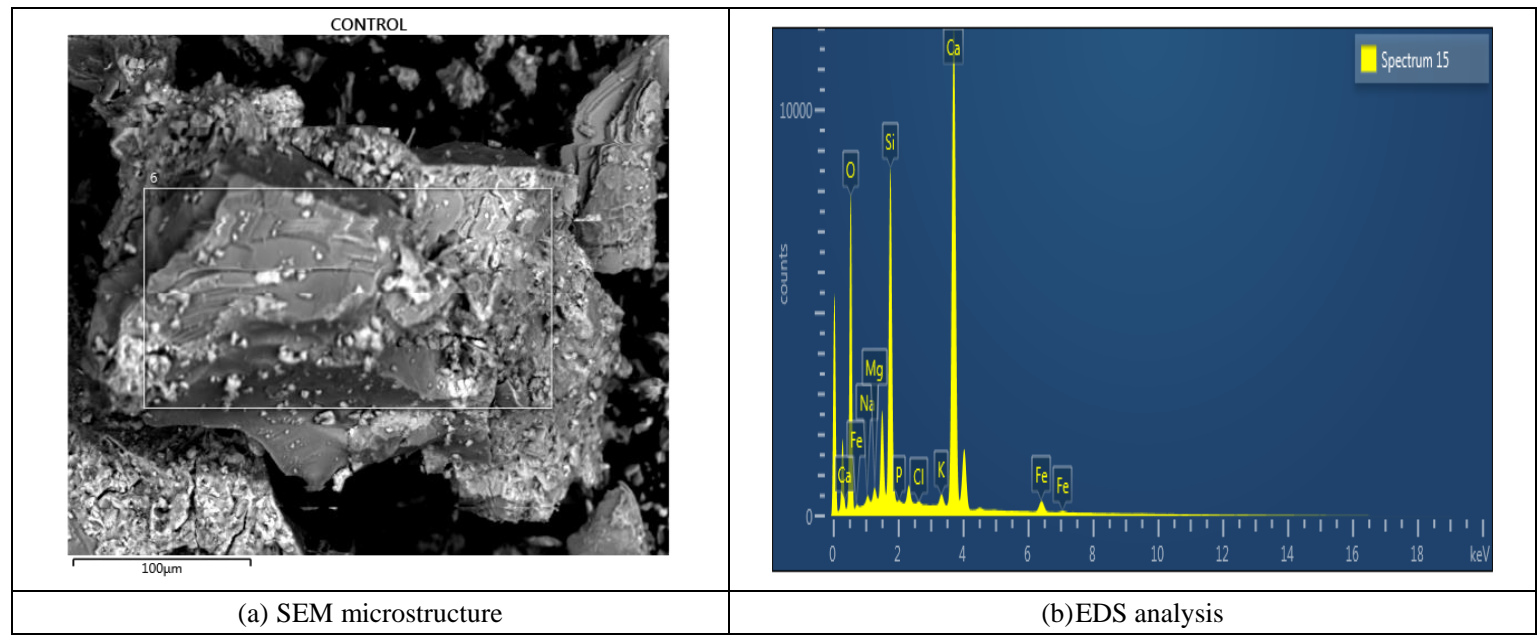

Fig.4. SEM Microstructure and EDS Analysis of Control Mix SBA0 (i.e 100\% OPC and 0\% SBA) after 28 days of Curing

As mentioned earlier, the cementitious matrix was observed under SEM. Microstructure obtained by SEM helped to determine the morphological structure of cement matrix sample. Fig. 4(a) presents the morphology of reference concrete (SBA0) sample containing $100 \%$ OPC and 0\% SBA by weight. SEM image shows that the majority of particles are irregularly shaped and porous in nature. The marked rectangle area in Fig. 4(a) was selected for EDS analysis. EDS analysis indicates the major elements are calcium, silica and oxygen in the cement paste and the trace elements are sodium, iron and magnesium as shown in Fig. 4(b). This fact is confirmed by the amount of whiter particles present in the cement matrix which indicates presence of large number of hydrated cement grains. The presence of oxygen is due to the fact that the materials present silica $\left(\mathrm{SiO}_{2}\right)$ and calcium oxide $(\mathrm{CaO})$.

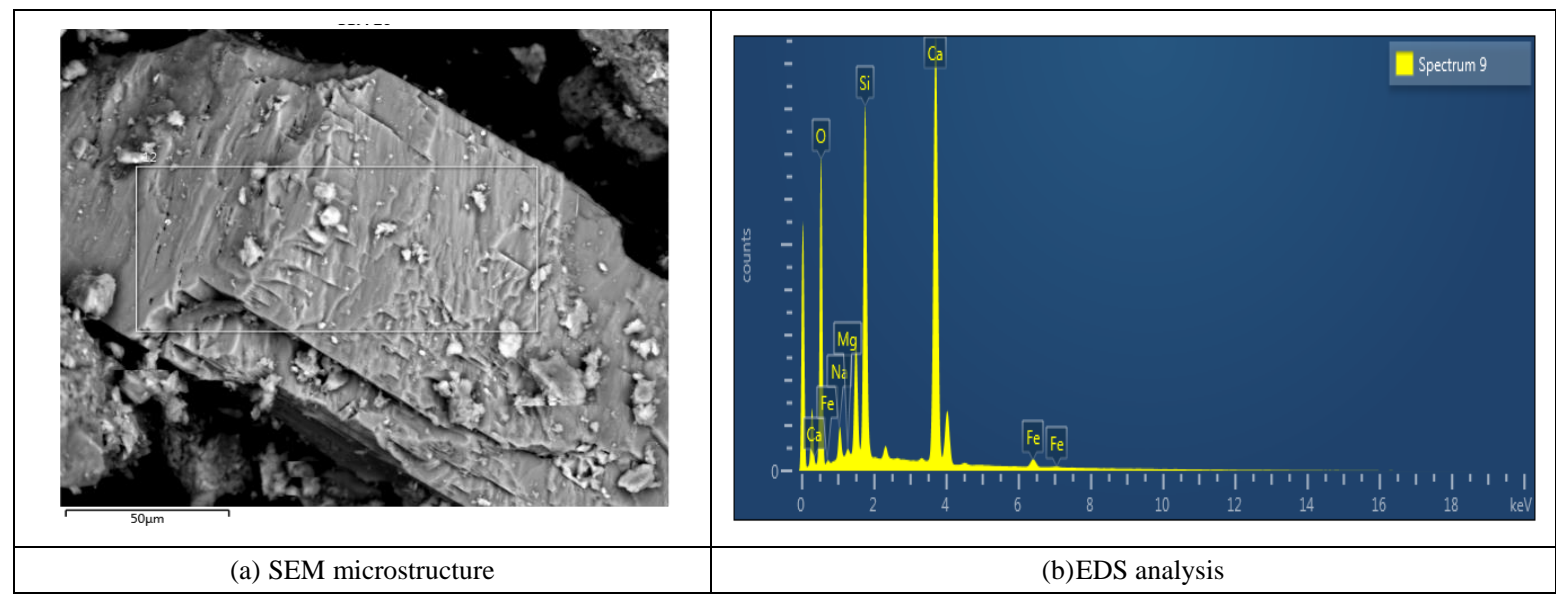

Fig.5. SEM Microstructure and EDS Analysis of SBA10 Blended Cement Concrete Mix (i.e. 90\% OPC and 10\% SBA) after 28 days of Curing 
Fig. 5(a) represents morphology of SBA10 blended cement concrete containing 90\% OPC and 10\% SBA by weight of the cross-section of the fractured surface from the compressive testing machine after 28 days of curing under controlled environment. The microstructure of SBA10 was very different from those of control mix SBA0 (as shown in Fig. 4a). SEM image (Fig. 5(a)) clearly indicates the dense microstructure and here also trace amounts of white particles present in the blended cement matrix which indicates the presence of hydrated cement grains. According to EDS analysis (marked rectangle area in Fig. 5(a)) shows the matrix of reaction products was composed of calcium $(\mathrm{Ca})$ and silica $(\mathrm{Si})$ as major elements and the other trace elements are magnesium $(\mathrm{Mg})$, sodium $(\mathrm{Na})$ and iron $(\mathrm{Fe})$ as shown in Fig. 5(b). The Si concentration in the SBA10 is higher than that registered in the SBA0 mix. The increase in Si content is due to the fact that SBA exhibits higher silica concentration (as seen in Table 5). The calcium concentration of SBA10 is lesser than that registered in SBA0. The reason being, reduction in cement content in the SBA10 mix as compared control units (SBA0).

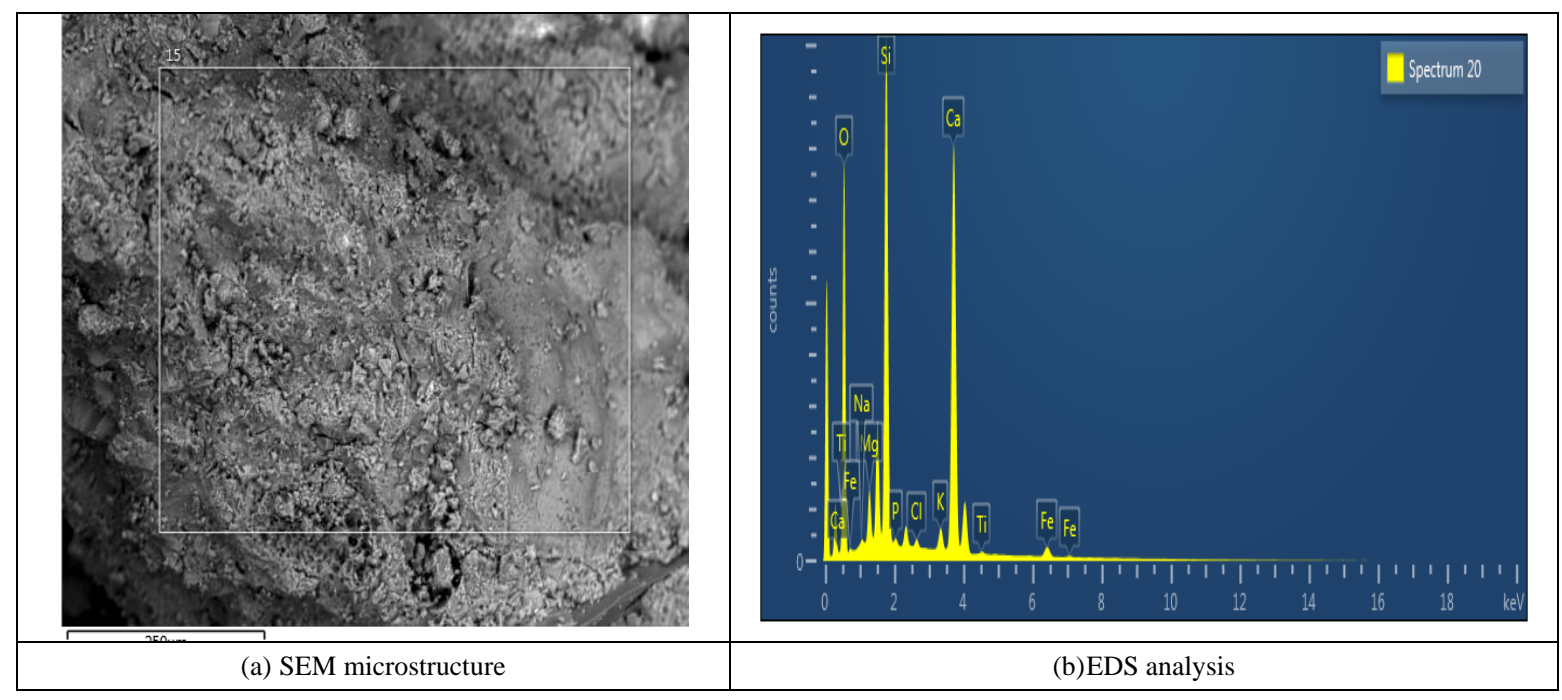

Fig.6. SEM Microstructure and EDS Analysis of SBA20 Blended Cement Concrete Mix (i.e. 80\% OPC and 20\% SBA) after 28 days of Curing

Fig. 6(a) represents microstructure of SBA20 blended cement concrete containing $80 \%$ OPC and $20 \%$ SBA, of the cross-section of the fractured surface from the compressive testing machine after 28 days of curing. The SEM image of SBA20 indicates dense cementitious matrix and homogeneous compared to control mix (SBA0) as shown in Fig. 6a. This fact is confirmed by the particle size analysis reported previously in Fig. 1, the presence of fine fibrous particles of SBA compared to OPC. The mean grain size of SBA and OPC are $1.3 \mathrm{~nm}$ and $1191.4 \mathrm{~nm}$ respectively. Fig. 6(b) presents the EDS analysis corresponding to the marked rectangle region in Fig. 6(a). As expected the major elements are silica ( $\mathrm{Si}$ ) and calcium $(\mathrm{Ca})$ which mainly contribute from sugarcane bagasse ash and also from cement. The EDS map (Fig. 6(b)) shows reduction in calcium concentration compared to SBA0 and SBA10 due to the reduction in cement content in SBA20 mix. On the other hand there is significant increase in Si concentration due to the increase in SBA particles in the SBA20 mix. Other elements such as sodium, magnesium, iron, potassium were observed in trace quantities. 


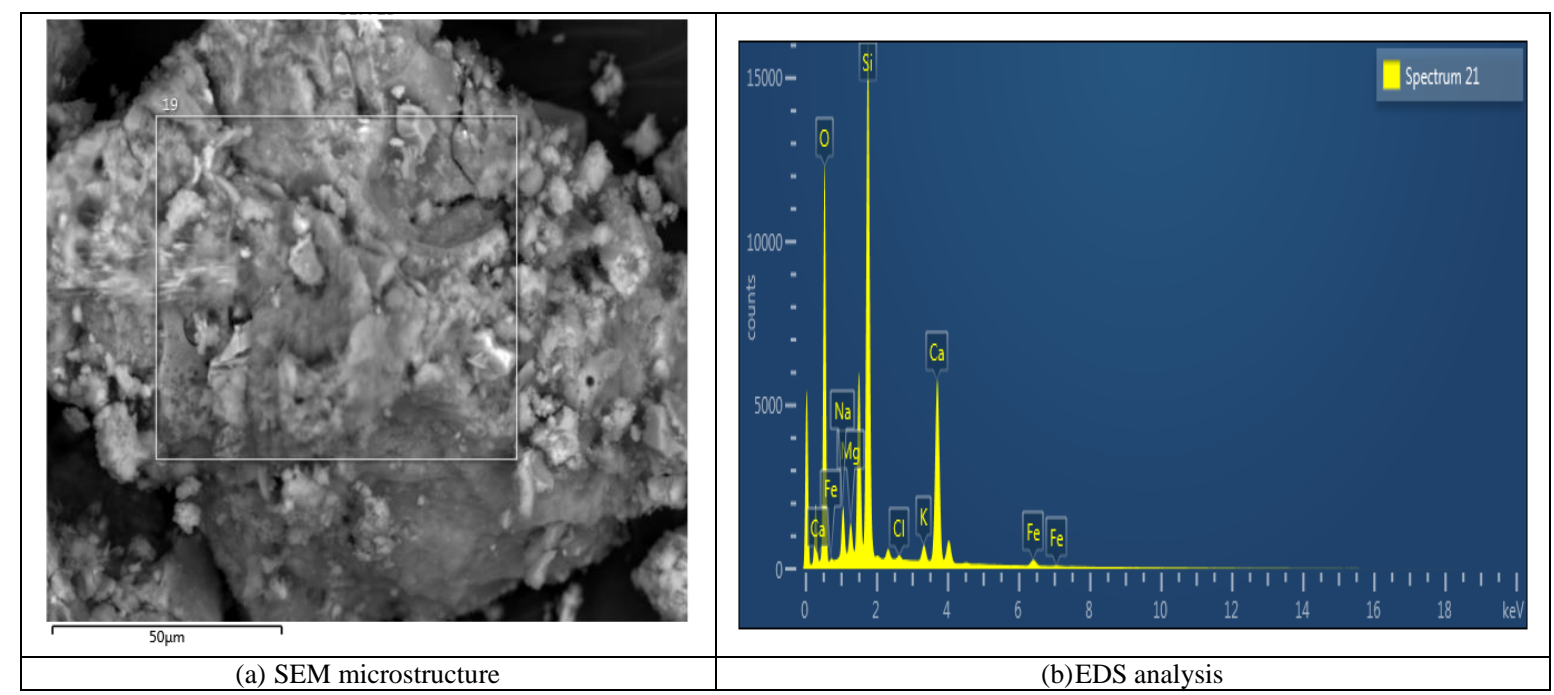

Fig.7. SEM Microstructure and EDS Analysis of SBA30 Blended Cement Concrete Mix (i.e. $70 \%$ OPC and $30 \%$ SBA) after 28 days of Curing

Fig. 7(a) section presents SEM image of microstructure of SBA30 blended cement concrete containing 70\% OPC and 30\% SBA of the broken surface from compression testing machine after 28 days of curing the specimen. It can be observed from Fig. 4 to 7, the microstructure of SBA30 is very different as compared to the microstructures of SBA0 to SBA20. This indicates the microstructure of SBA30 is less denser compared to SBA0 to SBA20. The EDS analysis was used for microanalysis to quantify the elements present in SBA30 blended cement concrete mix. According to the EDS spot analysis (rectangle marked in Fig. 7(a)) shows the matrix of reaction products was composed mainly by silica and it was also observed that the calcium concentration gradually decreases compared to SBA0, SBA10 and SBA20 mixes. The elemental composition of the cement matrix around the blended cement paste indicates less concentration of sodium, magnesium, chloride and iron as shown in Fig. 7(b).

\section{Conclusions}

The present study provides the microstructure and elemental composition of blended cement concrete at different cement replacement levels by sugarcane bagasse ash. Based on the results obtained, the following conclusions are drawn.

It is observed that SBA particles exhibit higher surface area and finer grain size as compared to OPC particles. The morphology of SBA particles shows spongy in nature while OPC particles are angular and irregular. Elemental analysis of SBA indicates that the fine fibrous particles contain predominately $\mathrm{Si}$ and $\mathrm{O}$ with trace quantities of $\mathrm{Ca}, \mathrm{K}, \mathrm{Fe}, \mathrm{Cl}, \mathrm{P}$ and $\mathrm{Mg}$. On the other hand, OPC particles contain predominately $\mathrm{Ca}, \mathrm{O}$ and $\mathrm{Si}$ with lesser amounts of $\mathrm{Al}, \mathrm{Fe}$ and $\mathrm{Na}$.

SEM images were taken on the fractured surface of blended cement mix (from SBA0 to SBA30) to examine the microstructure properties. Microstructure of blended cement mix presents dense matrix as the cement replacement level increases by SBA. EDS analysis was also carried out on the selected area of SEM images to determine the elemental composition of blended cement paste (from SBA0 to SBA30). EDS maps shows increase in Si concentration as the population of SBA particles increases in the cementitious matrix while that of $\mathrm{Ca}$ concentration decreases. 


\section{Acknowledgements}

The authors gratefully acknowledge to Dr. Padmalal Scientist F, National Centre for Earth Science Studies, Thiruvananthapuram, India for investigating the chemical analyses of pozzolonic materials used during the study period. Our sincere thanks to Mr. Arif, NIO, Dona Paula, Goa for conducting SEM-EDS analysis of the materials. The authors also acknowledge to Miss. Buruga Kezia, NITK, Surathkal for investigating the physical properties of sugarcane bagasse ash and Portland cement. The authors are indebted to Department of Civil and Chemical engineering. KLE Dr. M. S. Sheshagiri College of Engineering and Technology, Belgaum for all the crucial amenities provided for the experimentation.

\section{References}

[1] D.P.Kulkarni, "Cane Sugar Manufacture in India", The Sugar Technologists Association of India.

[2] STAI (Sugar Technologists Association of India). (2015). List of cane sugar factories (India, Bangladesh, Nepal, Pakistan \& Sri Lanka) and refineries \& distilleries 2014-2015.” New Delhi, India.

[3] G.C. Cordeiro, R.D. Toledo Filho, E.M.R. Fairbairn, Effect of calcination temperature on the pozzolanic activity of sugar cane bagasse ash. Construction and Building Materials 23 (2009) 3301-3303, Elsevier, doi:10.1016/j.conbuildmat.2009.02.013

[4] S. Deepika, G. Anand, A. Bahurudeen and Manu Santhanam. Construction Products with Sugarcane Bagasse Ash Binder. Journal of Materials in Civil Engineering, (C) ASCE, ISSN 0899-1561.

[5] Bahurudeen A, Santhanam M. Sugarcane bagasse ash - an alternative supplementary cementitious material. In: International conference on advances in civil engineering and chemistry of innovative materials, India; 2014. pp. 837-42.

[6] Cordeiro GC, Toledo Filho RD, Tavares LM, Fairbairn EMR. Pozzolanic activity and filler effect of sugar cane bagasse ash in Portland cement and lime mortars. Cement and Concrete Composites 2008: 30(5):410-8, Elsevier,doi:10.1016/j.cemconcomp.2008.01.001.

[7] Singh NB, Singh VD, Rai S. Hydration of bagasse ash-blended Portland cement. Cement and Concrete Research 2000: 30(9):1485-8.

[8] Ganesan K, Rajagopal K, Thangavel K. Evaluation of bagasse ash as supplementary cementitious material. Cement and Concrete Composites 2007; 29(6): 515-24, Elsevier. doi:10.1016/j.cemconcomp.2007.03.001.

[9] Cordeiro GC, Toledo Filho RD, Fairbairn EMR. Use of ultra-fine sugar cane bagasse ash as mineral admixture for concrete. ACI Mater J 2008; 105(5): 487-93.

[10] Guilherme Chagas Cordeiro, Romildo Dias Toledo Filho, Luís Marcelo Tavares, Eduardo de Moraes Rego Fairbairn. Ultrafine grinding of sugar cane bagasse ash for application as pozzolanic admixture in concrete. Cement and Concrete Research (2009); 39: 110-115, Elsevier, doi:10.1016/j.cemconres.2008.11.005.

[11] Nuntachai Chusilp, Chai Jaturapitakkul, Kraiwood Kiattikomol. Effects of LOI of ground bagasse ash on the compressive strength and sulfate resistance of mortars. Construction and Building Materials (2009); 23: 3523-3531, Elsevier, doi:10.1016/j.conbuildmat.2009.06.046.

[12] IS 8112: 1989, Indian Standard 43 Grade Ordinary Portland Cement -Specification, First Revision.

[13] IS 383-1970 Specification for coarse and fine aggregate from natural sources for concrete.

[14] IS 456: 2000, Indian Standard Plain and Reinforced Concrete- Code of Practice, Fourth Revision.

[15] Prashant O Modani and M R Vyawahare. Utilization of Bagasse Ash as a Partial Replacement of Fine Aggregate in Concrete. Chemical, Civil and Mechanical Engineering Tracks of 3rd Nirma University 
International Conference on Engineering (NUICONE 2012) Procedia Engineering 51 (2013) 25 - 29, Elsevier, doi: 10.1016/j.proeng.2013.01.007.

[16] H. Paiva, A. Velosa, P. Cachim, V.M. Ferreira, Effect of metakaolin dispersion on fresh and hardened state properties of concrete, Cement Concrete Research 4 (2012) 607-612.

\section{Authors' Profiles}

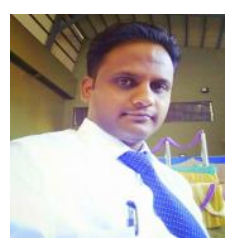

Prof. Chidanand Patil, is currently working as Assistant Professor in Civil Engineering Department, KLE DR. M.S.Shesagiri College of Engineering and Technology, Belgaum, Karnataka. He is having a teaching experience of 8 years and is a Ph.D research scholar in Visvesvaraya Technological University, Belagavi, India.

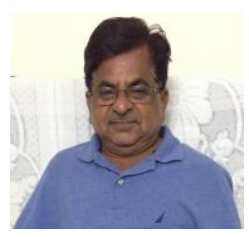

Dr. P.B.Kalburgi, is currently working as Professor in Civil Engineering Department, B.E.C., Bagalkoat. He has 20 years of teaching experience and 15 years of industrial experience. He has published around 20 technical papers in International/National Journals and proceedings of International/ National conferences.

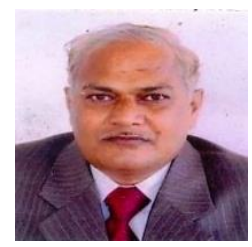

Dr. M.B.Patil, is currently working as Professor and Head of Civil Engineering Department, GSKSJTI, Bengaluru. He has more than 25 years of teaching experience and also 5 years of industrial experience. He has published and presented many technical papers in international and national conference. He is also consultant to P.W.D (Public Work Department) and N.H.A.I.(National Highway Authority of India)

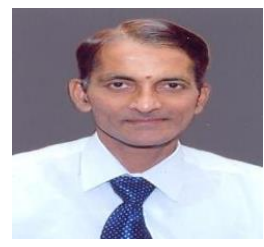

Dr. K. B. Prakash, is currently working as Professor and Head in Civil Engineering Department and Principal of Government Engineering College, Haveri, Karnataka. He has 27 years of teaching experience and 2 years of industrial experience. He has published around 200 technical papers in International/National Journals and proceedings of International/ National conferences.

How to cite this paper: Chidanand Patil, P.B.Kalburgi, M.B.Patil, K.B.Prakash,"An Investigation on the Micro Structural and Elemental Composition of Sugarcane Bagasse Ash Blended Concrete using SEM and EDS Technique", International Journal of Engineering and Manufacturing(IJEM), Vol.8, No.3, pp.54-66, 2018.DOI: $10.5815 / \mathrm{ijem} .2018 .03 .05$ 